\title{
Domain-specificity of $\mathrm{Cd}^{2+}$ and $\mathrm{Zn}^{2+}$ binding to rabbit liver metallothionein 2
}

\author{
Metal ion mobility in the formation of $\mathrm{Cd}_{4}$-metallothionein $\alpha$-fragment
}

\author{
Martin J. STILLMAN* and Andrzej J. ZELAZOWSKI \\ Department of Chemistry, University of Western Ontario, London, Ont. N6A 5B7, Canada
}

\begin{abstract}
The yield of the $\alpha$-fragment of rabbit liver metallothionein 2 was used to test the domain-specificity and mobility of $\mathrm{Cd}^{2+}$ and $\mathrm{Zn}^{2+}$ when bound to metallothionein. Increasing molar ratios of $\mathrm{Cd}^{2+}$ were added to either $\mathrm{Zn}_{7}$-metallothionein or the metal-ion-free apo-metallothionein. The enzyme subtilisin was used to digest those parts of the peptide chain that were not bound to $\mathrm{Cd}^{2+}$. Analysis of the digestion products was carried out by separation by polyacrylamide-gel electrophoresis. The chelation agent EDTA was used as a competitive chelator. It was found that the presence of excess EDTA greatly enhances the formation of the $\mathrm{Cd}_{4}$-metallothionein $\alpha$-fragment, and catalyses the complete digestion of all other the metal-ion-containing peptides, so that even $\mathrm{Cd}_{7}$-metallothionein, formed when 7 molar equivalents of $\mathrm{Cd}^{2+}$ are added to $\mathrm{Zn}_{7}$ metallothionein, is digested to the $\alpha$-fragment. These results suggest that the $\mathrm{Cd}^{2+}$ bound in the $\beta$-sites is very labile, much more labile than the kinetics of the off-reaction would suggest. The observation of significant amounts of $\alpha$-fragment on the gels, even when the stoichiometry of the metal ions initially present in the protein should not have resulted in much concentration of $\mathrm{Cd}_{4}-\alpha$-fragment clusters, indicates that as the digestion proceeds the metal ions move to sites that form complete clusters and therefore selectively protect that part of the peptide chain from digestion. We also find that rabbit $\mathrm{Cd}_{4}$-metallothionein $2 \alpha$-fragment stains near to the top of the gel, in complete contrast with the location of rat $\mathrm{Cd}_{4}$-metallothionein $2 \alpha$ fragment. This difference in the mobilities suggests that the $\alpha$-fragment prepared from rabbit metallothionein 2 is much less negatively charged than the analogous protein fragment prepared from rat liver metallothionein 2 .
\end{abstract}

\section{INTRODUCTION}

The protein metallothionein (MT) contains 20 cysteine residues out of a total of 61 amino acid residues (Kägi \& Vallee, 1961). MT can be readily isolated from the livers and kidneys of a wide variety of mammals, although rats and rabbits have provided much of the protein used in spectroscopic studies. A remarkably wide range of metal ions bind to MT, both in vivo (Piotrowski et al., 1979) and in vitro (Nielsen et al., 1985). However, it has been the two-domain structure adopted for $\mathrm{Cd}^{2+}, \mathrm{Cu}^{2+}$ and $\mathrm{Zn}^{2+}$ (and probably all other metal ions that bind to $\mathrm{MT}$ ) that has attracted most attention in structural studies. MT has been well studied by a range of spectroscopic techniques (Kägi \& Vallee, 1961; Otvos \& Armitage, 1980; Neuhaus et al., 1985; Furey et al., 1986; Stillman et al., 1987a; Stillman \& Zelazowski, 1988). Definitive information on the geometry of the binding sites for $\mathrm{Cd}^{2+}$ and $\mathrm{Zn}^{2+}$ has been obtained from ${ }^{113} \mathrm{Cd}$ n.m.r. (Otvos \& Armitage, 1980), two-dimensional ${ }^{1} \mathrm{H}$ n.m.r. (Neuhaus et al., 1985) and X-ray-diffraction studies (Furey et al., 1986). The MT molecule exhibits the unique property of binding either $7 \mathrm{Cd}^{2+}$ ions or $7 \mathrm{Zn}^{2+}$ ions, or a mixture of 7 of these metal ions, in two domains, named $\alpha$ and $\beta$ (Otvos \& Armitage, 1980). Stability constants were reported first by Kägi, summarized by Nordberg \&
Kojima (1979), and by Petering et al. (1987) as approx. $10^{11} \mathrm{M}$ for $\mathrm{Zn}^{2+}$ binding to MT and $10^{15} \mathrm{M}$ for $\mathrm{Cd}^{2+}$ binding to MT, both at $\mathrm{pH} 7$. Absorption, c.d., magneticc.d. and emission spectroscopic studies have provided considerable detail about the stoichiometry of the metalion replacement reactions that take place when $\mathrm{Cd}^{2+}$ (Stillman et al., 1987b; Stillman \& Zelazowski, 1988), $\mathrm{Cu}^{2+}$ (Winge \& Miklossy, 1982; Nielsen et al., 1985; Gasyna et al., 1988) or $\mathrm{Hg}^{2+}$ (Stillman et al., 1983; Cai \& Stillman, $1988 b$ ) is added to apo-MT, $\mathrm{Zn}_{7}-\mathrm{MT}$ or Cd,Zn-MT. Emission spectra for Cu-MT (Stillman et al., 1985; Gasyna et al., 1988) and $\mathrm{Ag}^{+}$(Stillman et al., 1988) and c.d. spectra of $\mathrm{Cd}^{2+}$ binding to $\mathrm{Zn}-\mathrm{MT}$ and apo-MT (Stillman et al., 1987b; Stillman \& Zelazowski, 1988) have shown particular sensitivity towards cluster formation within MT. However, only very recently have studies concentrating on the initial site for binding of these metal ions appeared (Nettesheim et al., 1985; Stillman et al., 1987b; Stillman \& Zelazowski, 1988).

In this present paper we examine how the differences between binding-site formation constants controls the yield of $\mathrm{Cd}_{4}-\alpha$-fragment made by adding $\mathrm{Cd}^{2+}$ to either apo-MT or $\mathrm{Zn}^{2+}$-containing protein, using the enzyme subtilisin to carry out selective digestion of the protein (Winge \& Miklossy, 1982), and EDTA as a competitive chelator.

Abbreviation used: MT, metallothionein

* To whom correspondence should be addressed. 


\section{MATERIALS AND METHODS}

$\mathrm{Zn}_{7}$-MT 2 was purified from the liver of a rabbit injected with $\mathrm{ZnSO}_{4}$ at the rate of $20 \mathrm{mg}$ of $\mathrm{Zn} / \mathrm{kg}$ body wt. every second day over a 2 -week period. The protein was purified as previously reported (Zelazowski et al., 1980). Apo-MT 2 was prepared from rabbit Zn-MT 2 by gel filtration on Sephadex G-25 (Stillman et al., 1987b). Protein concentrations were assayed by titration of the RSH groups with 5,5'-dithiobis-(2nitrobenzoic acid) (Birchmeir \& Christen, 1971) or by determination of the metal content by atomic absorption spectrometry. Polyacrylamide-gel electrophoresis was performed by using the methods of Jovin et al. (1964). Portions ( $100 \mu \mathrm{g}, 1.4 \mathrm{nmol})$ of the protein were dissolved in $100 \mathrm{ml}$ of Tris buffer and the $\mathrm{pH}$ was adjusted to between 7 and 8 with $\mathrm{HCl}$. The solutions were saturated with Ar to prevent oxidation. A 77-fold excess of EDTA was added, together with subtilisin (Sigma Chemical Co.), which was added at an enzyme/protein ratio of $1: 20(\mathrm{w} / \mathrm{w})$, and the solution was incubated at room temperature for $2 \mathrm{~h}$. The products in the final solution were separated by polyacrylamide-gel electrophoresis. The final gels were immersed in a solution of Coomassie Blue R-250 (in an aqueous solution of ethanol, trichloroacetic acid, sulphosalicylic acid and acetic acid) overnight to fix and stain the protein. Then $5 \mathrm{~mm}$ sections of duplicate gels were digested with $\mathrm{H}_{2} \mathrm{O}_{2}$ overnight at $80^{\circ} \mathrm{C}$ to solubilize the gel. After evaporation of the solvent, the solid was redissolved in $\mathrm{HCl}$ and applied to the atomic absorption spectrometer for analysis of metal content. The atomic-absorption-spectrometry values for the Cd content are plotted for each gel adjacent to the gel photographs.

\section{RESULTS}

Partial digestion by subtilisin of rabbit liver $\mathrm{Zn}_{7}-\mathrm{MT} 2$ and apo-MT 2 to which various amounts of $\mathrm{Cd}^{2+}$ had been added was used to investigate how the varied occupancy of the $\alpha$ - and $\beta$-domains by $\mathrm{Cd}^{2+}$ and $\mathrm{Zn}^{2+}$ affects the formation of a specific product, the $\mathrm{Cd}^{2+}$ saturated $\mathrm{Cd}_{4}$-MT $2 \alpha$-fragment.

It is well known that the section of the peptide chain that is involved in $\mathrm{Cd}^{2+}$-thiolate cluster formation is afforded protection against digestion by subtilisin (Winge $\&$ Miklossy, 1982). The relative yield of $\mathrm{Cd}_{4}-\alpha \mathrm{MT}$ fragment compared with $\mathrm{Zn}_{7}-\mathrm{MT}$ or fully saturated $\mathrm{Cd}_{7}$-MT shows how the different cluster stabilities affect the mechanism of the digestion with subtilisin after the mixing of known stoichiometric ratios of $\mathrm{Zn}^{2+}$ and $\mathrm{Cd}^{2+}$ with the protein. The experiment probes the binding constants for filled domains within the protein, i.e. $\mathrm{Cd}_{4}-\alpha$-domain versus $\mathrm{Cd}_{3}-\beta$-domain versus the mixed $\mathrm{Cd}, \mathrm{Zn}$ - $\alpha$-domain and $\mathrm{Cd}, \mathrm{Zn}$ - $\beta$-domain.

\section{Digestion of $\mathrm{Zn}_{7}$-MT 2 partially metallated with $\mathbf{C d}^{2+}$}

Subtilisin was mixed with separate solutions of the $\mathrm{Zn}$-MT protein to which different amounts of $\mathrm{Cd}^{2+}$ had been added. The solutions used were prepared as follows: portions of $\mathrm{Cd}^{2+}$, with increasing concentrations between 1 and 7 molar equivalents, in steps of 1 molar equivalent, together with excess EDTA, were mixed with separate samples of $\mathrm{Zn}_{7}-\mathrm{MT} 2$, and subtilisin was added. These solutions were incubated for $2 \mathrm{~h}$ at room temperature and then applied to a polyacrylamide gel and the products were separated by electrophoresis.

Fig. 1(a) shows the stained gels obtained after electrophoresis of eight samples of Zn-MT 2. Lane 0 is the native $\mathrm{Zn}_{7}-\mathrm{MT}$, with no $\mathrm{Cd}^{2+}$ added. This gel provides a calibration of the mobilities for both $\mathrm{Zn}_{7}-\mathrm{MT}$ and $\mathrm{Cd}_{7}-\mathrm{MT}$, because the $\mathrm{Cd}_{7}-\mathrm{MT}$ is expected to behave identically with the $\mathrm{Zn}_{7}-\mathrm{MT}$ as there are no differences in binding geometry (both tetrahedral) or overall charge. The development of the $\mathrm{Cd}_{7}-\mathrm{MT}$ band at the same location in Fig. 3 confirms this. This calibration for rabbit liver $\mathrm{Cd}_{4}-\alpha \mathrm{MT} 2$ fragment is provided in lanes $3-6$. We can use these data because, under the conditions used for the solutions separated by the gels in Fig. 2, the only product expected is $\mathrm{Cd}_{4}-\alpha \mathrm{MT}$ fragment.

For lanes $1-7$ in Fig. 1 the protein was treated as described above so that the number of the lane corresponds to the number of molar equivalents of $\mathrm{Cd}^{2+}$ added to the $\mathrm{Zn}-\mathrm{MT}$. Thus, before addition of subtilisin, the protein added to lane 1 could be written as $\mathrm{Cd}_{1}, \mathrm{Zn}_{6}-\mathrm{MT}$, lane 2 as $\mathrm{Cd}_{2}, \mathrm{Zn}_{3}-\mathrm{MT}$, up to lane 7 , in which the initial $\mathrm{Zn}_{7}-\mathrm{MT}$ was fully saturated with $\mathrm{Cd}^{2+}$ to give $\mathrm{Cd}_{7}-\mathrm{MT}$. From our spectral studies we know that at room temperature $\mathrm{Cd}^{2+}$ will be distributed across both domains up to $\mathrm{Cd}_{6}, \mathrm{Zn}_{1}-\mathrm{MT}$ (Stillman et al., 1987b; Stillman \& Zelazowski, 1988). The solutions were applied to the gel at the top of the Figure. Native $\mathrm{Zn}_{7}-\mathrm{MT}$ (in lane 0) moves to a position near the bottom (indicated by the black star), while the intact $\alpha$-domain, $\mathrm{Cd}_{4}-\alpha \mathrm{MT} 2$ fragment, remains at a position near the top of the gel (seen as the band in each of lanes 1-7, and indicated by a white star within a black circle). The gel patterns are different when compared with similar separations carried out for rat liver MT2. In those cases the $\alpha$-fragment was detected nearer the middle of the gel (Winge \& Miklossy, 1982; Zelazowski et al., 1984).

Fig. 1(b) shows the distribution of $\mathrm{Cd}$, measured by atomic absorption spectrometry, for $5 \mathrm{~mm}$ sections of each gel. The intensity of the band due to $\mathrm{Cd}_{4}-\alpha \mathrm{MT}$ fragment in Fig. 1 $(a)$ increases as the stoichiometry of the original protein changes from $\mathrm{Cd}_{1}, \mathrm{Zn}_{6}-\mathrm{MT}$ to $\mathrm{Cd}_{4}, \mathrm{Zn}_{3}$ MT, with little other proteinaceous material being discerned. In accord with the staining, the concentration of $\mathrm{Cd}$ also increases up to 5 molar equivalents of $\mathrm{Cd}^{2+}$ added. As expected, in the stoichiometric range of 5-7 molar equivalents of $\mathrm{Cd}$, that is from $\mathrm{Cd}_{4}, \mathrm{Zn}_{3}-\mathrm{MT}$ to $\mathrm{Cd}_{7}$-MT (lanes 4-7), there is little increase in intensity of $\mathrm{Cd}_{4}-\alpha \mathrm{MT}$ fragment, which indicates that the maximum amount of the $\alpha$-fragment made in this experiment is reached when between 4 and 5 molar equivalents of $\mathrm{Cd}^{2+}$ are added to the $\mathrm{Zn}-\mathrm{MT}$. Surprisingly, there is almost no indication of the presence of undigested $\mathrm{Cd}_{7}-\mathrm{MT}$, even when 7 molar equivalents of $\mathrm{Cd}^{2+}$ have been added. The $\mathrm{Cd}_{7}$-MT would be observed at the same position as the $\mathrm{Zn}_{7}$-MT (lane 0). Very slight staining is found in this region in lanes 6 and 7, which could represent a minimal concentration of $\mathrm{Cd}_{7}-\mathrm{MT}$; however, there is little $\mathrm{Cd}^{2+}$ associated with the protein at this point on the gel. The band near the centre of the gel (white star) has not been identified, but it might have been produced as a result of incomplete digestion of protein (Klauser et al., 1983). The atomic-absorption-spectrometric analysis shows that a small amount of $\mathrm{Cd}^{2+}$ binds to this material.

Clearly, in the presence of EDTA, digestion by subtilisin results in the formation of $\alpha$-fragment (left-hand side of Fig. 1a), together with progressively more un- 
(a)

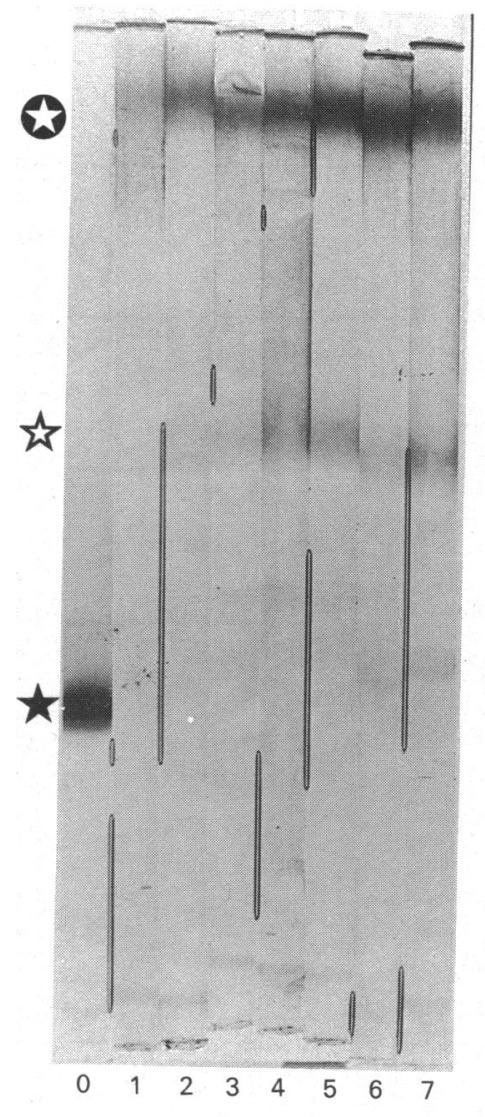

(b)

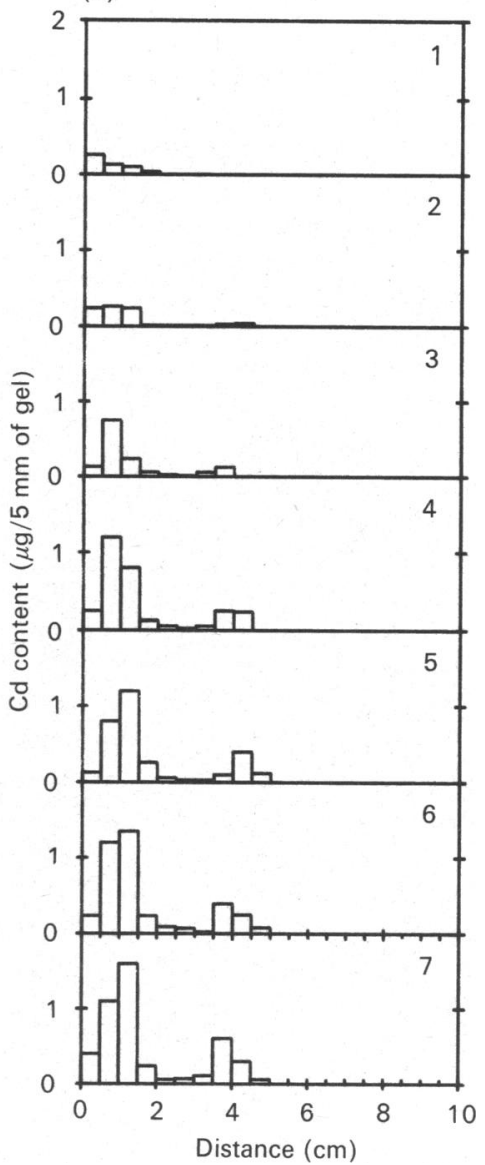

Fig. 1. Set of polyacrylamide gels photographed after electrophoresis of the MT fragments formed by subtilisin digestion of rabbit liver $\mathrm{Zn}_{\mathbf{7}}$-MT 2 in the presence of EDTA

(a) There are eight lanes. $\mathrm{Cd}^{2+}$ was added (lanes 1-7) to a solution of $\mathrm{Zn}_{7}-\mathrm{MT}$ and EDTA (in approx. 77-fold excess), and subtilisin was then added. The lane markings indicate the number of molar equivalents of $\mathrm{Cd}^{2+}$ added to the $\mathrm{Zn}-\mathrm{MT}$. For lane 0 no $\mathrm{Cd}^{2+}$ was added. $\mathrm{Cd}_{4}-\alpha \mathrm{MT}$ fragment stains at the top, marked by a white star within a black circle; $\mathrm{Cd}_{7}-\mathrm{MT}$ and $\mathrm{Zn}_{7}-\mathrm{MT}$ stain at the bottom of the gel (marked by a black star). The white star marks material of unknown origin. Protein was added to the gel at the top of the photograph. $(b)$ The seven panels show the Cd concentrations measured for 5 mm segments down each of the seven gels (lanes 1-7) in $(a)$. The top of the gel appears on the left of the panel. The panel number coincides with the number of molar equivalents of $\mathrm{Cd}^{2+}$ added to the $\mathrm{Zn}-\mathrm{MT}$ in the presence of EDTA, before digestion by subtilisin.

identified Cd-containing material that is indicated by the stain with above 3 molar equivalents of $\mathrm{Cd}^{2-}$. Although the $\mathrm{Cd}_{3}-\mathrm{S}_{9}$ cluster in the $\beta$-domain of the intact protein forms at some stage after 5 molar equivalents of $\mathrm{Cd}^{2+}$ added (Stillman et al., 1987b), the $\beta$-domain is not protected from digestion in the presence of the EDTA. It is significant that under these experimental conditions almost no $\mathrm{Cd}_{7}-\mathrm{MT}$ forms, even after the maximum amount of $\mathrm{Cd}_{4}-\alpha \mathrm{MT}$ fragment forms with 4-5 molar equivalents of $\mathrm{Cd}^{2+}$ added. As displayed in the stained gel and by the metal analyses, all protein in excess $\alpha$ fragment is digested.

\section{Digestion of apo-MT 2 partially metallated with $\mathrm{Cd}^{2+}$ in the presence of EDTA}

When apo-MT 2 was used as a starting material (Fig. $2 a$ ) we found a considerable increase in protein-free $\mathrm{Cd}^{2+}$, which is located at the bottom of the gel, a decrease in $\alpha$-fragment formation and, again, minimal undigested $\mathrm{Cd}_{7}-\mathrm{MT}$. In these experiments molar-equivalent portions of $\mathrm{Cd}^{2+}$ were added to seven different solutions of rabbit liver apo-MT 2 at $\mathrm{pH} 2$, and the $\mathrm{pH}$ was adjusted up to 8. Lane numbers indicate the number of molar equivalents of $\mathrm{Cd}^{2+}$ added to the apo-MT. Lane 8 has no $\mathrm{Cd}^{2+}$ added; a solution of apo-MT and subtilisin was added to the gel. Spectral studies (Stillman et al., 1987b) show that $\mathrm{Cd}^{2+}$ added to apo-MT specifically fills the $\alpha$-domain first to form $\mathrm{Cd}_{4}-\alpha \mathrm{MT}$ fragment, then the $\beta$-domain. Even though subtilisin was added to $\mathrm{Cd}_{7}-\mathrm{MT}$ in lane 7 , which from previous studies (Nielsen \& Winge, 1983) would have been expected to be resistant to enzymic digestion, Fig. 2(a) shows only minor staining, this indicating the presence of only small amounts of undigested $\mathrm{Cd}_{7}-\mathrm{MT}$. Fig. 2(b) shows the $\mathrm{Cd}$ distribution along the gels displayed in Fig. $2(a)$. The pattern of the $\mathrm{Cd}$ distribution is quite different when compared with the $\mathrm{Zn}$-MT gels. Most of the Cd in these gels is found at the bottom of the gel by the atomic-absorption-spectrometric analysis. Because there is no Coomassie Blue stain, we suggest that this $\mathrm{Cd}$ is in the form of the EDTA complex. The concentration of $\mathrm{Cd}$ in the $\alpha$-fragment region up to the $\mathrm{Cd}_{4}-\mathrm{MT}$ point is about the same as in 
(a)

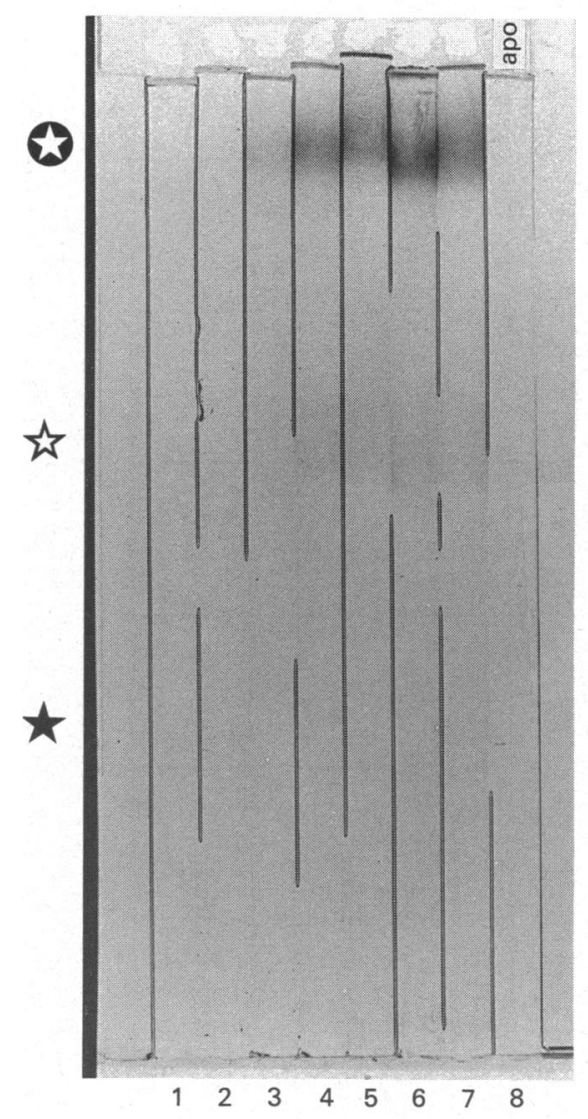

(b)

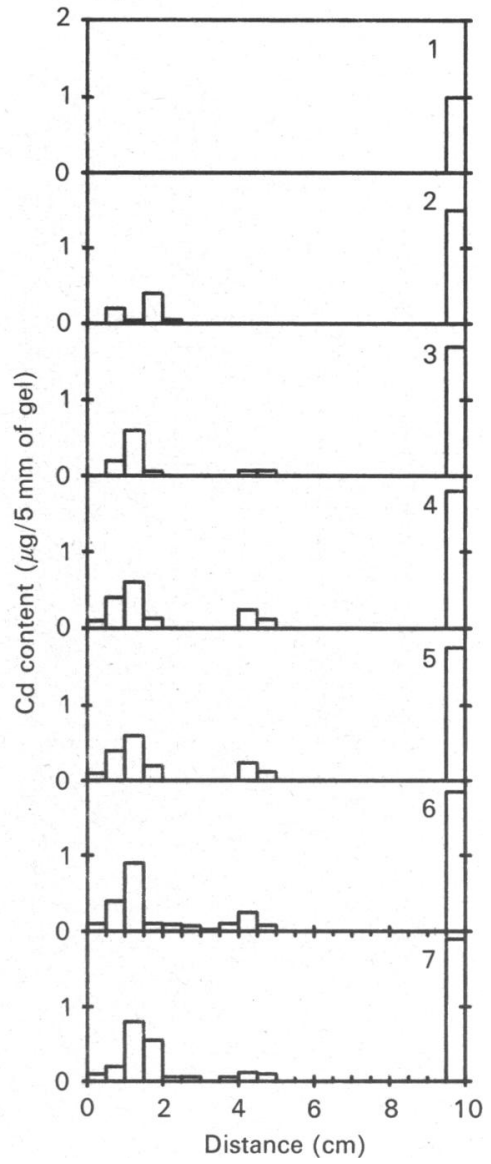

Fig. 2. Set of polyacrylamide gels photographed after electrophoresis of the MT fragments formed by subtilisin digestion of apo-MT 2 in the presence of EDTA (in 77-fold excess)

(a) There are eight lanes. $\mathrm{Cd}^{2+}$ was added (lanes 1-7) to solutions of apo-MT and EDTA, and subtilisin was then added. The lane markings indicate the number of molar equivalents of $\mathrm{Cd}^{2+}$ added to the apo-MT. For lane 8 , no $\mathrm{Cd}^{2+}$ was added. The regions in which stained lines are seen are the same as for Fig. $1(a)$. (b) The seven panels show the Cd concentrations measured for $5 \mathrm{~mm}$ segments down each of the seven gels (lanes 1-7) in (a). The top of the gel appears on the left of the panel. The panel number coincides with the number of molar equivalents of $\mathrm{Cd}^{2+}$ added to the apo-MT in the presence of EDTA, before digestion by subtilisin.

Fig. 1. After this point, the concentration of $\mathrm{Cd}$ in the $\alpha$-fragment region is constant.

\section{Digestion of apo-MT 2 partially metallated with $\mathrm{Cd}^{2+}$ in the absence of EDTA}

$\mathrm{Cd}^{2+}$ (1-7 molar equivalents) was added to portions of apo-MT at $\mathrm{pH} \mathrm{2,} \mathrm{then} \mathrm{adjusted} \mathrm{to} \mathrm{pH} 8$ with Tris buffer, and subtilisin was mixed with the protein for $2 \mathrm{~h}$. Clearly, there is a significant difference between the staining in Fig. 2(a) (apo-MT, with EDTA) and Fig. 3(a) (apo-MT, with no EDTA added). Unlike the Cd distribution observed for the other experiments, we now find (Fig. $3 b$ ) that $\mathrm{Cd}$ is distributed in two main areas of the gel. In Fig. 3(a) new staining appears in the $\mathrm{Cd}_{7}-\mathrm{MT}$ region of the gel (three-quarters of the way down, indicated by the black star) for all samples in which 4 or more molar equivalents of $\mathrm{Cd}^{2+}$ have been added to the apo-MT. At the same time as the $\mathrm{Cd}_{7}-\mathrm{MT}$ staining increases in intensity (from 5 to 6 to 7 molar equivalents of $\mathrm{Cd}^{2+}$ ), staining the $\mathrm{Cd}_{4}-\alpha \mathrm{MT}$ fragment region (the top of the gel, indicated by the white star within a black circle) decreases in intensity, until no $\alpha$-fragment is detected when 7 molar equivalents of $\mathrm{Cd}^{2+}$ have been added. There is a significant increase of $\mathrm{Cd}$ in the $\mathrm{Cd}_{7}-\mathrm{MT}$ region at the expense of $\mathrm{Cd}_{4}-\alpha \mathrm{MT}$ fragment once more than 4 molar equivalents of $\mathrm{Cd}^{2+}$ have been added to the apo-MT. Little protein-free $\mathrm{Cd}^{2+}$ collects in the sections of the gel near the bottom. The atomic-absorptionspectrometry results show more clearly than the protein staining how both the $\mathrm{Cd}_{4}-\alpha \mathrm{MT}$ fragment and $\mathrm{Cd}_{3}-\mathrm{MT}$ exist in the gel even with only 1 molar equivalent of $\mathrm{Cd}^{2+}$ added.

In a separate series of experiments, $\mathrm{Zn}^{2+}$ was added to apo-MT 2, and the digestions were carried out as described above. In the presence of EDTA, subtilisin completely digested the protein at all stoichiometric $\mathrm{Zn} / \mathrm{MT}$ ratios. No bands were detected after staining. No Figure is shown here.

\section{DISCUSSION}

Native MT containing a mixture of both $\mathrm{Cd}$ and $\mathrm{Zn}$ that is isolated from rat and rabbit livers exhibits considerable domain-specificity (Otvos \& Armitage, 

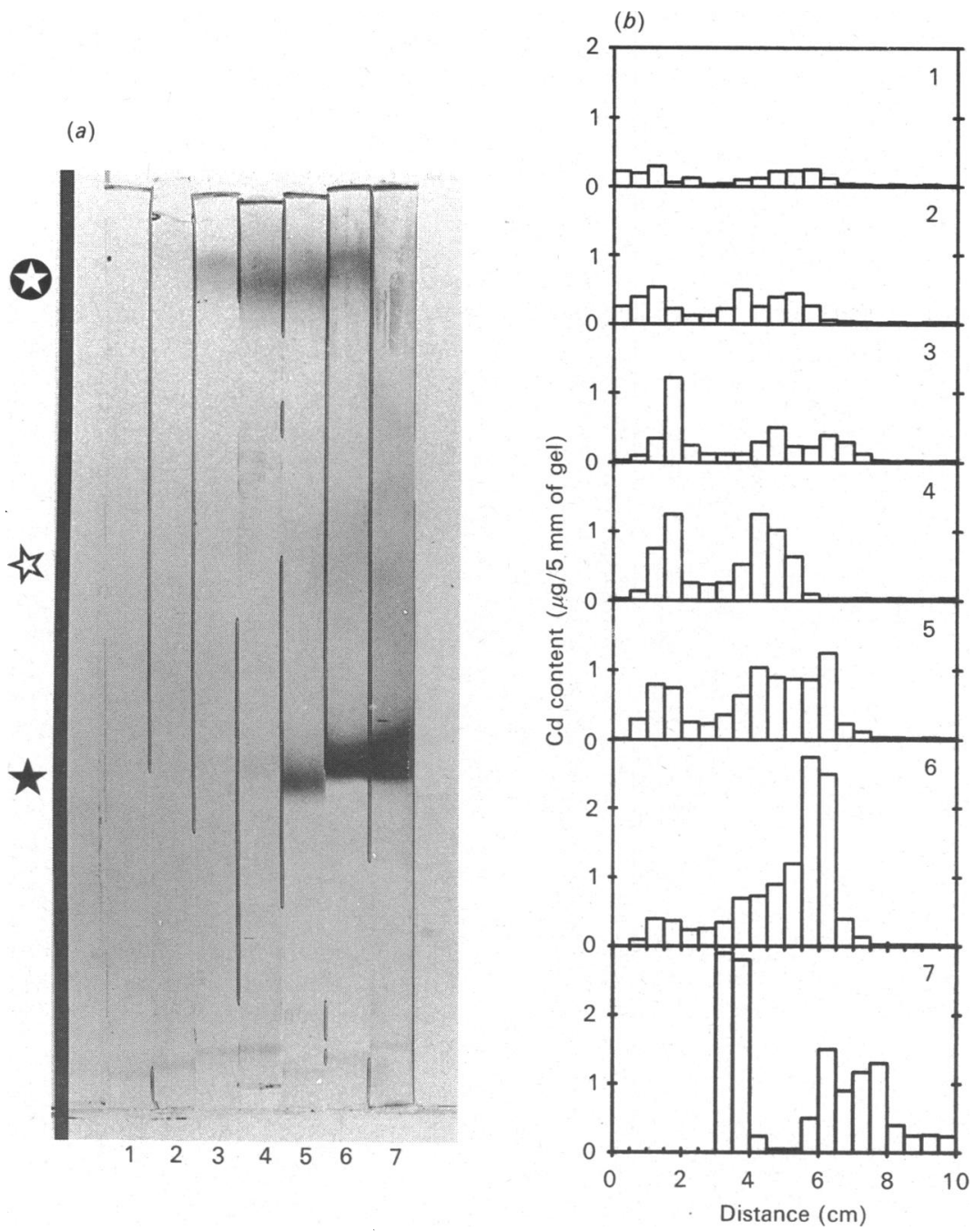

Fig. 3. Set of polyacrylamide gels photographed after electrophoresis of the MT fragments formed by subtilisin digestion of apo-MT in the absence of EDTA

(a) There are seven lanes. $\mathrm{Cd}^{2+}$ was added to solutions of apo-MT in the absence of EDTA, and subtilisin was then added. The lane markings indicate the number of molar equivalents of $\mathrm{Cd}^{2+}$ added to the apo-MT. The $\alpha$-fragment stains at the top and $\mathrm{Zn}_{7}-\mathrm{MT}$ stains at the bottom of the gel. Protein was added to the gel at the top of the photograph. (b) The seven panels show the CD concentrations measured for $5 \mathrm{~mm}$ segments down each of the seven gels (lanes 1-7) in (a). The top of the gel appears on the left of the panel. The panel number coincides with the number of molar equivalents of $\mathrm{Cd}^{2+}$ added to the apo-MT in the absence of EDTA, before digestion by subtilisin.

1980; Winge \& Miklossy, 1982; Nielsen et al., 1985; Furey et al., 1986). The stoichiometric $\mathrm{Cd} / \mathrm{Zn}$ ratio for native liver protein often approximates $5: 2$, with the $C d$ localized in the $\alpha$-domain and the $\mathrm{Zn}$ localized in the $\beta$ domain (Otvos \& Armitage, 1980; Nielsen et al., 1985). Except for $\mathrm{Cd}^{2+}$ binding selectively to the $\alpha$-domain in apo-MT (Winge \& Miklossy, 1982; Nielsen \& Winge, 1983; Stillman et al., 1987b; Stillman \& Zelazowski, 1988) and $\mathrm{Cu}^{2+}$ binding selectively to the $\beta$-domain (Nielsen et al., 1985) in apo-MT, the domain-selectivity in the initial binding step for many metal ions has not yet been established conclusively. ${ }^{113} \mathrm{Cd}$ n.m.r. (Nettesheim et al., 1985) and optical spectra recorded during $\mathrm{Cd}^{2+}$ binding to both apo-MT and $\mathrm{Zn}_{7}-\mathrm{MT}$ (Stillman et al., $1987 b$; Stillman \& Zelazowski, 1988) have suggested that the domain specificity observed in vitro depends on whether the binding sites were occupied by $\mathrm{Zn}$ or whether the thiolate groups were protonated before binding the
$\mathrm{Cd}^{2+}$ (as in apo-MT). We have previously suggested (Stillman et al., 1987b; Stillman \& Zelazowski, 1988), using c.d. spectroscopy, that $\mathrm{Cd}^{2+}$ binds to $\mathrm{Zn}_{7}-\mathrm{MT}$ in a distributed manner without significant cluster preference. Similar results were found in ${ }^{113} \mathrm{Cd}$ n.m.r. titrations (Nettesheim et al., 1985).

At room temperature these distributed arrangements are relatively stable (Byrd \& Winge, 1986). However, native $\mathrm{Cd}_{5}, \mathrm{Zn}_{2}-\mathrm{MT}$ is found with Cd primarily bound in the $\alpha$-domain and the $\mathrm{Zn}$ bound in the $\beta$-domain, an arrangement not readily achieved in vitro (Stillman \& Zelazowski, 1988). The MT-bound Cd can rearrange into the domain-specific species if the temperature is raised (Stillman et al., 1987b; Stillman \& Zelazowski, 1988); the effect is especially pronounced for metal-ionbinding experiments carried out below $0^{\circ} \mathrm{C}$ (Stillman \& Zelazowski, 1988). In a separate study (M. J. Stillman, Z. Gasyna \& A. J. Zelazowski, unpublished work), we 
have found that $\mathrm{Cd}$ and $\mathrm{Zn}$ rearrange between the $\alpha$ and $\beta$-domains following the mixing of stoichiometric amounts of $\mathrm{Zn}_{7}-\mathrm{MT}$ and $\mathrm{Cd}_{7}-\mathrm{MT}$. This reaction occurs very much faster than expected for the low concentrations of free metal ion available with the high formation constants measured for $\mathrm{Cd}^{2+}$ and $\mathrm{Zn}^{2+}$ binding to MT (Kägi \& Vallee, 1961). These results lead to questions concerning the mechanism of formation of the domainspecific native $\mathrm{Cd}, \mathrm{Zn}-\mathrm{MT}$.

The experiments described in this paper compare the stabilities of the clusters of metal ions in the $\alpha$ - and $\beta$-domains. With the $10^{4}$-fold difference in stability constants for $\mathrm{Cd}^{2+}$ with respect to $\mathrm{Zn}^{2+}$ binding to $\mathrm{MT}$ (Nordberg \& Kojima, 1979; Petering et al., 1987), the $\mathrm{Cd}^{2+}$ readily displaces bound $\mathrm{Zn}$. As digestion takes place, resistance (which translates into a marked decrease in the extent of digestion within a certain time period) is observed for those parts of the protein that contain metal ions. The experiments with subtilisin illustrate that the $\mathrm{Cd}$ and $\mathrm{Zn}$ atoms bound in MT are quite mobile. When the distributed model for $\mathrm{Cd}^{2+}$ binding to $\mathrm{Zn}_{7}-\mathrm{MT}$ operates, the product formed at room temperature following the addition of $\mathrm{Cd}^{2+}$ to $\mathrm{Zn}_{7}-\mathrm{MT}$ is a protein with $\mathrm{Zn}$ and $\mathrm{Cd}$ distributed between both domains up to the 5 molar equivalents of Cd level (Stillman \& Zelazowski, 1988).

The essential feature in these experiments is that we can use subtilisin to digest those parts of the peptide that are not strongly bound to $\mathrm{Cd}^{2+}$. EDTA will extract $\mathrm{Zn}$ from $\mathrm{Zn}$-containing MT, for example the mixed-metal Cd,Zn-MT (Nicholson \& Sadler, 1987), but not the Cd in such protein. Therefore we might predict that, when the distributed model operates following the addition of $\mathrm{Cd}^{2+}$ to $\mathrm{Zn}-\mathrm{MT}$, excess EDTA should selectively extract $\mathrm{Zn}$ from the protein, leaving a polypeptide chain clipped, or cross-linked, by regions of Cd-SR-Cd unit distributed across both domains. Such a structure should be resistant to proteolytic digestion in all regions where $\mathrm{Cd}^{2+}$-thiolate binding is present. Therefore digesting such a partially occupied protein should lead to a chaotic mixture of MT fragments, because there would be no complete clusters units available to protect the whole of either the $\alpha$ - or the $\beta$-domain. This large number of partially digested fragments would produce many bands, or just a broad smudge, on polyacrylamide-gel electrophoresis.

The picture that we find is completely different from this predicted one. Under the experimental conditions used here with excess EDTA (Figs. $1 a$ and $2 a$ ) we form, almost exclusively, Cd-containing $\alpha$-fragment. There is only one additional, unidentified, band observed. Significantly, we cannot detect any staining due to $\mathrm{Cd}_{7}-\mathrm{MT}$, even when 7 molar equivalents of $\mathrm{Cd}^{2+}$ are added to either $\mathrm{Zn}_{7}-\mathrm{MT}$ or apo-MT, as long as excess EDTA is used in the incubation solution.

The presence of the EDTA is clearly an important factor in determining this selectivity. When the experiments are carried out in the absence of EDTA, quite different products are formed. In particular, large amounts of $\mathrm{Cd}_{7}-\mathrm{MT}$ are formed and remain undigested, even when there are empty $\mathrm{Cd}^{2+}$-binding sites in other MT molecules. For example, both $\mathrm{Cd}_{4}-\alpha \mathrm{MT}$ fragment and $\mathrm{Cd}_{7}-\mathrm{MT}$ form when only 1 molar equivalent of $\mathrm{Cd}^{2+}$ has been added to the apo-MT. We illustrate the reactions that take place in Fig. 4. Because of the very great difference between the reactions taking place in the presence and in the absence of EDTA, we suggest that

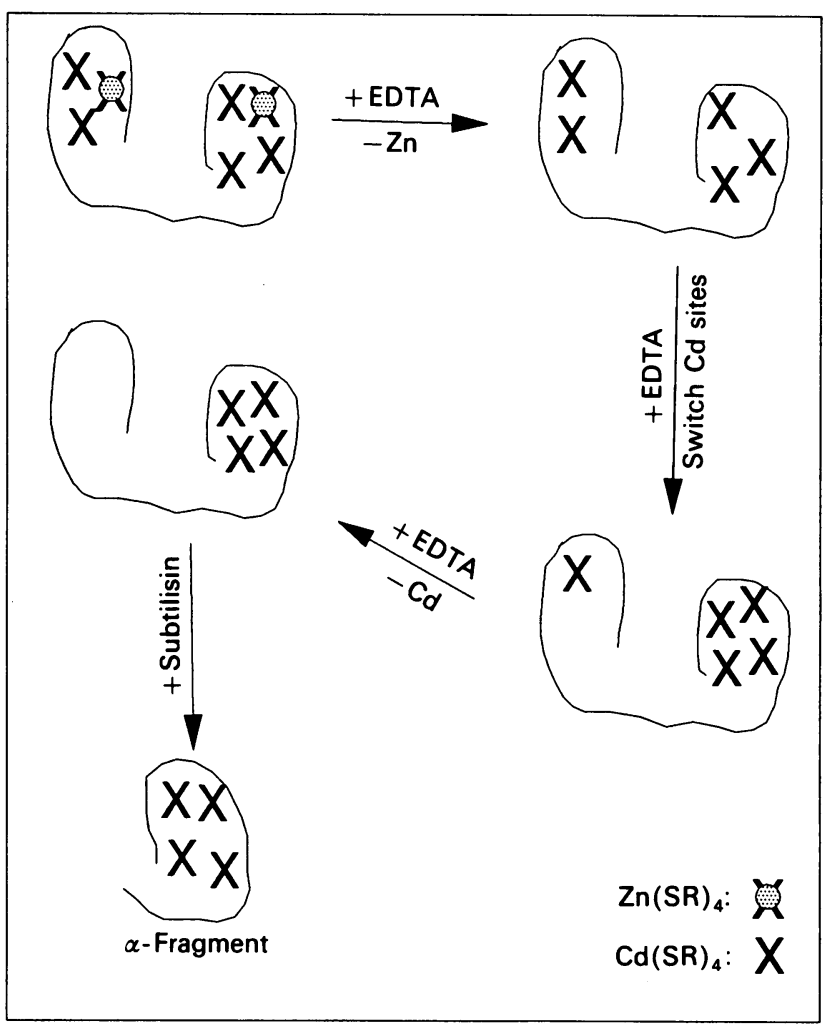

Fig. 4. Schematic representation of the reaction sequence when $\mathrm{Cd}_{5}, \mathrm{Zn}_{2}-\mathrm{MT}$ is mixed with EDTA and then partially digested by subtilisin

In the first step, the EDTA removes $\mathrm{Zn}$ from the protein, leaving a mixture of RS-Cd-SR cross-linked units and unco-ordinated thiolate groups, RSH. In the second step EDTA acts as a carrier for $\mathrm{Cd}$ in the $\beta$-domain and catalyses the rearrangement of $\mathrm{Cd}$ from the $\beta$-domain to the $\alpha$-domain. EDTA may then chelate the $\mathrm{Cd}$ remaining in the $\beta$-domain, leaving the $\beta$-domain peptide chain available for digestion.

EDTA not only competes for $\mathrm{Zn}$ bound to the protein but also acts as an intermediary in redistributing $\mathrm{Cd}$ from the $\beta$-domain to the $\alpha$-domain once $\mathrm{Zn}$ has been removed to form $\mathrm{Zn}^{2+}$-EDTA complexes. This is the last step before digestion. Thus the EDTA catalyses the rearrangement of metals to the thermodynamic rather than the kinetic, binding-site arrangement. This mechanism does not appear to operate in the absence of the subtilisin (Nicholson \& Sadler, 1987). Clearly, the metalion-binding sites in the MT are not energetically equal. Formation of complete clusters, both $\mathrm{Cd}_{4}$ and $\mathrm{Cd}_{3}$, appears to be more energetically favourable than formation of partially filled clusters.

A second scenario might be that EDTA chelates only the $\mathrm{Zn}$, leaving a series of vacant binding sites in the $\alpha$ and $\beta$-domains. $\mathrm{Cd}$ in the $\beta$-domain could then migrate to the $\alpha$-domain without the use of the carrier. The experiments shown in Fig. 3 examine this effect because it has been proposed that $\mathrm{Cd}^{2+}$ binds selectively to the $\alpha$ domain in titrations of apo-MT (Nettesheim et al., 1985; Stillman et al., 1987b). What we find in the absence of EDTA is that several different fragments are left over after the digestion. However, there are two main fragments with significant concentrations, and these appear 
with mobilities the same as those of $\mathrm{Cd}_{4}-\alpha \mathrm{MT}$ fragment and the undigested $\mathrm{Cd}_{7}-\mathrm{MT}$. The lack of the single uniform product that is observed with EDTA strongly suggests that the $\mathrm{Cd}$ is not mobile enough within this time scale ( $2 \mathrm{~h}$ at room temperature) so that the subtilisin digests the kinetic product, which in the solution contains a distribution of the two most stable configurations, i.e. $\mathrm{Cd}_{4}-\alpha \mathrm{MT}$ fragment and $\mathrm{Cd}_{7}-\mathrm{MT}$, between 1 molar equivalent and 7 molar equivalents of $\mathrm{Cd}^{2+}$ added to the solution. This implies that for $\mathrm{Cd}$ to migrate completely from the $\beta$ - to the $\alpha$-domain at Cd/MT stoichiometric ratios less than 4:1 a carrier is necessary. In our case this is EDTA. The sequence of events that occur during these reactions is described in Fig. 4. The consequence of such a scenario is the following sequence of stability constants: $K_{\mathrm{f}}\left(\mathrm{Cd}_{4}-\alpha\right.$-domain $)>K_{\mathrm{f}}\left(\mathrm{Cd}^{2+}-\right.$ EDTA $)>K_{\mathrm{f}}\left(\mathrm{Cd}_{7}-\mathrm{MT}\right)$ $\approx K_{\mathrm{f}}\left(\mathrm{Cd}_{3}-\beta\right.$-domain $)$.

A major consequence of this type of chemical equilibrium is that there can be an accumulation of $\mathrm{Cd}$ in one of the two clusters, e.g. Cd in the $\alpha$-cluster may not be as labile as $\mathrm{Cd}$ in the $\beta$-cluster, which can lead to an observed binding preference in vivo. Rearrangement during chemical procedures carried out after the initial metal-ion-binding has occurred could result in the preferential binding for many metal ions that has been well documented by Nielsen and co-workers (Nielsen \& Winge, 1983; Nielsen et al., 1985).

In this present study we are testing the various models for metal-ion binding to MT against very simple experimental results. However, we find that the predicted outcome of the experiments is not observed. During the addition of $\mathrm{Cd}^{2+}$ to $\mathrm{Zn}_{7}-\mathrm{MT}$, we would expect that when the $\mathrm{Cd}$ exceeded the capacity of the $\alpha$-domain (4 molar equivalents) the $\mathrm{Cd}$ would accumulate in the $\beta$-domain, displacing the $\mathrm{Zn}$ (Winge \& Miklossy, 1982; Nielsen et al., 1985). From competitive binding studies with EDTA (Li et al., 1980) and immobilized EDTA (Chelex100) (Cai \& Stillman, 1988a), we would expect that the $\mathrm{Cd}^{2+}$ would bind to the $\beta$-domain tighter than it would to the EDTA [Petering et al. (1987) report that the stability constant for $\mathrm{Cd}^{2+}$ binding to $\mathrm{MT}$ is $10^{2}$ times greater than for $\mathrm{Cd}^{2+}$ binding to EDTA]. However, our data show that simply incubating $\mathrm{Cd}_{3}$-MT with EDTA and subtilisin for $2 \mathrm{~h}$ is sufficient to remove the $3 \mathrm{Cd}$ atoms from the $\beta$-domain. This strongly suggests that the lability of the $\mathrm{Cd}$ in the $\beta$-domain may be similar to that of the $\mathrm{Zn}$ in the $\beta$-domain. It requires several days of incubation under these same conditions to pull out the $\mathrm{Cd}$ from the $\alpha$-domain (Winge \& Miklossy, 1982).

Finally, from these experiments we have observed that there is a significant difference in the relative mobilities of the $\mathrm{Cd}_{4}-\alpha \mathrm{MT} 2$ fragments from the rat and the rabbit. On electrophoresis $\alpha$-fragment produced from rabbit MT 2 moves at a significantly slower pace compared with the rat $\mathrm{Cd}_{4}-\alpha \mathrm{MT} 2$ fragment. We find that the protein mobilities on these gels are very reproducible over several years. We have previously (Zelazowski et al., 1984) reported gels showing the separation of the products of identical reactions carried out with rat liver protein. In this 1984 paper, the rat liver $\mathrm{Cd}_{4}-\alpha$ MT 2 fragment stains near our 'white star' symbol, in the middle of the gels in Figs. 1-3. This is in a completely different region from that where the rabbit liver $\mathrm{Cd}_{4}-\alpha \mathrm{MT} 2$ fragment is found. The difference in mobilities suggests that rabbit $\alpha$-fragment is much less negatively charged than is the rat $\alpha$-fragment. We have recently also found that rabbit MT
2 protein behaves quite differently in its reaction with $\mathrm{Hg}^{2+}$ when compared with the analogous protein from the rat. Whereas the $\mathrm{Hg}_{18}$-MT species that is formed from rabbit liver MT 2 is characterized by a strong c.d. spectrum, which we have interpreted as arising from a particularly tightly wound peptide (Cai \& Stillman, $1988 \mathrm{~b}$ ), we do not find the same type of c.d. spectrum for the $\mathrm{Hg}$-containing rat liver MT 2. It is possible that both of these observations are related to significant differences in the metal-ion-binding capabilities of the rabbit MT 2.

What is the physiological significance of these results? We can speculate that metals (Cd in this case) also stabilize MT in vivo, making it resistant to enzyme proteolysis. Because the $\mathrm{Cd}$ in the $\beta$-domain is not bound tightly, exchange with $\mathrm{Zn}^{2+}$ could readily take place forming the $\mathrm{Cd}_{4}, \mathrm{Zn}_{3}-\mathrm{MT}$ species, the native protein with domain-specificity that is isolated from liver tissue. This model implies that the $\beta$-domain is able to bind metal ions much more freely than is the $\alpha$-domain.

\section{CONCLUSIONS}

The formation of $\mathrm{Cd}_{4}-\alpha \mathrm{MT}$ fragment has been used to determine the extent of digestion of MT by subtilisin. Digestion of the protein depends both on the metal loading and on the presence or the absence of a metaltransfer agent, a competitive chelator such as EDTA.

The experiments discussed above show that: (1) in the presence of EDTA, only $\mathrm{Cd}_{4}-\alpha \mathrm{MT}$ fragment is formed following proteolytic digestion, with no evidence of $\mathrm{Cd}_{7}-\mathrm{MT}$, even when 7 molar equivalents of $\mathrm{Cd}^{2+}$ have been added; (2) Cd located in the $\beta$-domain in MT is as labile as $\mathrm{Zn}$ in the $\beta$-domain, with respect to chelation by EDTA; (3) these results suggest that a metal-transfer agent could operate in vivo to catalyse the rearrangement of $\mathrm{Cd}$ bound to $\mathrm{Zn}-\mathrm{MT}$ in a distributed manner, so that the domain-specific $\mathrm{Cd}_{4}, \mathrm{Zn}_{3}-\mathrm{MT}$ is formed in tissue and is isolated as the native protein; (4) rabbit liver $\mathrm{Cd}_{4}-\mathrm{MT}$ $\alpha$-fragment is much less negatively charged than the analogous rat liver protein.

We thank the National Science and Engineering Research Council of Canada for funding under the Strategic Grants (Open) program. We are associated with the Centre for Chemical Physics and the Photochemistry Unit at the University of Western Ontario. This is Publication no. 415 of the Photochemistry Unit.

\section{REFERENCES}

Birchmeir, W. \& Christen, P. (1971) FEBS Lett. 18, 208-213

Byrd, J. \& Winge, D. R. (1986) Arch. Biochem. Biophys. 250, 233-237

Cai, W. \& Stillman, M. J. (1988a) Inorg. Chim. Acta 152, $111-115$

Cai, W. \& Stillman, M. J. (1988b) J. Am. Chem. Soc. 110, 7872-7873

Furey, W. F., Robbins, A. H., Clancy, L. L., Winge, D. R., Wang, B. C. \& Stout, C. D. (1986) Science 231, 704-710

Gasyna, Z., Zelazowski, A. J., Green, A. R., Ough, E. \& Stillman, M. J. (1988) Inorg. Chim. Acta 153, 115-118

Jovin, T., Chrambach, A. \& Naughton, M. A. (1964) Anal. Biochem. 9, 351-369

Kägi, J. H. R. \& Vallee, B. (1961) J. Biol. Chem. 236, 2435-2442 Klauser, S., Kägi, J. H. R. \& Wilson, K. J. (1983) Biochem. J. 209, 71-80

Li, T.-Y., Kraker, A. J., Shaw, C. F., III \& Petering, D. H. (1980) Proc. Natl. Acad. Sci. U.S.A. 77, 6334-6338 
Nettesheim, D. G., Engeseth, H. R. \& Otvos, J. D. (1985) Biochemistry 24, 6744-6751

Neuhaus, D., Wagner, G., Vašák, M., Kägi, J. H. R. \& Wüthrich, K. (1985) Eur. J. Biochem. 151, 257-273

Nicholson, J. K. \& Sadler, P. J. (1987) Proc. Int. Conf. Metallothioneins 2nd, 1985: Experientia Suppl. 52, 191-201

Nielsen, K. B. \& Winge, D. R. (1983) J. Biol. Chem. 258, 13063-13069

Nielsen, K. B., Atkin, C. L. \& Winge, D. R. (1985) J. Biol. Chem. 260, 5342-5350

Nordberg, M. \& Kojima, Y. (1979) in Metallothioneins (Kägi, J. H. R. \& Nordberg, M., eds.), pp. 41-124, Birkhäuser, Basel

Otvos, J. D. \& Armitage, I. M. (1980) Proc. Natl. Acad. Sci. U.S.A. 77, 7094-7098

Petering, D. M., Krezoski, S., Villalobos, J., Shaw, C. F. \& Otvos, J. D. (1987) Proc. Int. Conf. Metallothioneins 2nd. 1985: Experientia Suppl. 52, 573-580

Piotrowski, J. K., Szymanska, J. A., Mogilnicka, E. A. \& Zelazowski, A. J. (1979) in Metallothioneins (Kägi, J. H. R. \& Nordberg, M., eds.), pp. 363-371, Birkhäuser, Basel

Received 3 January 1989/13 March 1989; accepted 28 March 1989
Stillman, M. J. \& Zelazowski, A. J. (1988) J. Biol. Chem. 263, $6128-6133$

Stillman, M. J., Law, A. Y. C. \& Szymanska, J. A. (1983) in Chemical Toxicology and Clinical Chemistry of Metals (Brown, S. S. \& Savory, J., eds.), pp. 271-274, Academic Press, New York

Stillman, M. J., Law, A. Y. C., Cai, W. \& Zelazowski, A. J. (1987a) Proc. Int. Conf. Metallothioneins 2nd, 1985: Experientia Suppl. 52, 203-211

Stillman, M. J., Cai, W. \& Zelazowski, A. J. (1987b) J. Biol. Chem. 262, 4538-4548

Stillman, M. J., Zelazowski, A. J. \& Gasyna, Z. (1988) FEBS Lett. 240, 159-162

Winge, D. R. \& Miklossy, K. A. (1982) J. Biol. Chem. 257, 3471-3476

Zelazowski, A. J., Szymanska, J. A. \& Witas, H. (1980) Prep. Biochem. 10, 495-505

Zelazowski, A., Szymanska, J. A., Law, A. Y. C. \& Stillman, M. J. (1984) J. Biol. Chem. 259, 12960-12963 